\title{
AVALIAÇÃO DA CAMADA NITRETADA POR DESCARGAS ELETRICAS DO AÇO SAE 52100 TEMPERADO E REVENIDO*
}

\author{
Steferson Ferreira de Oliveira ${ }^{1}$ \\ Ernane Rodrigues da Silva² \\ Marcelo Araújo Câmara ${ }^{3}$ \\ Rafael Morais Ataíde Murta ${ }^{4}$
}

\section{Resumo}

A máquina convencional de usinagem por descargas elétricas (EDM) é utilizada no processo de nitretação por descargas elétricas (NDE), pois permite enriquecer a superfície de um substrato de aço SAE $52100 \mathrm{com}$ nitretos em meio a uma solução dielétrica composta por água deionizada e ureia. O objetivo do presente trabalho é caracterizar as camadas formadas ao utilizar uma solução dielétrica $(30 \mathrm{~g} / \mathrm{I})$ como fonte de nitrogênio e comparar as propriedades obtidas quando se utiliza eletrodo de cobre eletrolítico. As caracterizações das amostras no processo foram por meio das técnicas de microscopia óptica (OM), microscopia eletrônica de varredura (MEV) e microdureza Vickers $(\mathrm{HV})$, revelando a formação de uma camada uniforme e endurecida de nitretos, recoberta por uma camada branca (Zona Refundida), como comprovado por difração de Raio-X (DRX) a formação de compostos com nitrogênio. As camadas formadas no eletrodo peça temperado e revenido foram mais espessas do que as que formaram no eletrodo peça esferoidizado. Para avaliar o desempenho do processo de usinagem, foram utilizados parâmetros como taxa de remoção de material (TRM), taxa de desgaste do eletrodo ferramenta (TD) e desgaste volumétrico (DVR).

Palavras-chave: EDM; Nitretação por descargas elétricas; Implantação iônica; caracterização da camada nitretada.

\section{EVALUATION OF NITRATE LAYER BY ELECTRIC DISCHARGE OF QUENCHED AND TEMPERED SAE 52100 STEEL}

\section{Abstract}

The conventional electric discharge machining (EDM) is used in the electrical discharge nitriding process (NDE), as it allows to enrich the surface of a SAE 52100 steel substrate with nitrides in a dielectric solution composed of deionized water and urea. The aim of the present paper is to characterize the layers formed by using a dielectric solution $(30 \mathrm{~g} / \mathrm{I})$ as a source of nitrogen and compare the properties obtained when using electrolytic copper electrode. The characterization of the samples in the process was done using optical microscopy (OM), scanning electron microscopy (SEM) and Vickers microhardness (HV), revealing the formation of a uniform and hardened layer of nitrites, covered by a white layer (Zone Refounded), as proved by $X$-ray diffraction (XRD) the formation of compounds with nitrogen. The layers of quenched and tempered part electrode were thicker than that of the spheroidized part electrode. To evaluate the performance of the machining process, parameters such as material removal rate (TRM), wear rate of the tool electrode (TD) and volumetric wear (DVR) were used.

Keywords: EDM; Electric Discharge Nitriding; Ion implantion; Nitrited layer chacterization. 
1 Engenheiro Metalurgista, Mestrando, Bolsista, Departamento de Engenharia de Materiais, Centro Federal de Educação Tecnológica de Minas Gerais, Belo Horizonte, Minas Gerais, Brasil.

2 Matemático, Doutor em Engenharia Mecânica, Professor, Departamento de Engenharia de Materiais, Centro Federal de Educação Tecnológica de Minas Gerais, Belo Horizonte, Minas Gerais, Brasil.

3 Engenheiro Mecânico, Doutor em Engenharia Mecânica, Professor, Departamento de Engenharia Mecânica, Universidade Federal de Minas Gerais, Belo Horizonte, Minas Gerais, Brasil.

4 Engenheiro Mecânico, Mestrando, Departamento de Engenharia de Materiais, Centro Federal de Educação Tecnológica de Minas Gerais, Belo Horizonte, Minas Gerais, Brasil. 


\section{INTRODUÇÃO}

O aço SAE 52100 possui elevado teor de carbono, ligado ao cromo, sendo muito utilizado em ferramentas para trabalho a frio como: brocas, alargadores, machos, ferramentas para repuxo de tornos, punções, ferramentas para extrusão a frio, facas para papel, etc. Utiliza-se também em componentes como rolamentos em partes como: pistas internas e externas, esferas, roletes e agulhas [1].

Após tratamentos térmicos de têmpera e revenimento, tem-se ganhos na dureza do material de valores que variam entre 62-66 HRC. O tratamento térmico de têmpera é comumente realizado com temperatura de austenitização situada entre $840^{\circ} \mathrm{C} \mathrm{a} 870^{\circ} \mathrm{C}$ e devido ao elevado teor de carbono, realiza-se o resfriamento em óleo com agitação e aquecimento entre $40^{\circ} \mathrm{C} / 70^{\circ} \mathrm{C}$. O revenimento é realizado após a têmpera entre as temperaturas de $120-200^{\circ} \mathrm{C}[1]$.

O cromo é responsável pela estabilização e tamanho dos carbetos no tratamento térmico de esferoidização, assim no aço temperado e revenido encontram-se carbetos finamente dispersos na matriz, além de obter uma transformação de fase rápida e homogênea da ferrita-austenita [1,2].

A contribuição de vários tribologistas ao longo do tempo, possibilitou o desenvolvimento da engenharia de superfície e em diferentes aplicações como tratamentos térmicos e revestimentos que podem aprimorar as propriedades e desempenho através do controle do atrito e desgaste.Com isso, é possível combinar a alta resistência mecânica de um substrato com um revestimento que melhora as propriedades ao desgaste, temperatura e corrosão, com o objetivo de obter propriedades localizadas e melhor desempenho $[3,4]$.

O conhecimento e a tecnologia desenvolvida no advento do comando numérico computadorizado (Computer numerical control-CNC) em 1980, trouxe grandes avanços no processo de usinagem por descargas elétricas (Electrical discharge machining-EDM). As contribuições tecnológicas resultaram no aprimoramento do processo de nitretação por descargas elétricas (NDE) [5].

"O processo de nitretação é um método de endurecimento superficial para aumentar a resistência ao desgaste por deslizamento e à fadiga de superfícies metálicas das matrizes e moldes" (6). No processo a plasma que é um dos mais utilizados a reação não ocorre somente na superfície, pois há difusão de átomos de nitrogênio para o substrato e formação de uma fina camada de nitretos de ferro na superfície associada a uma zona de difusão espessa e dura [6,7].

O método utilizado na NDE é o de implantação iônica no qual o nitrogênio é adicionado a superfície do substrato por meio de um canal de plasma formado ao abrir o arco elétrico que se formar entre o eletrodo peça e o eletrodo ferramenta (8). O processo de nitretação por descargas elétricas utiliza solução de água deionizada e ureia como fluido dielétrico, promoveu aumento na dureza e resistência ao desgaste por deslizamento do aço AISI H13 bem como formação de camadas de até $20 \mu \mathrm{m}$ com nitretos abaixo da zona refundida [9]. 
Experimentos realizados no aço AISI 4140 mostraram que a nitretação por NDE tem possibilidade de aplicação tecnológica e pode ser utilizado também em processos alternativos à EDM, seja variando a concentração de ureia na água ou utilização de eletrodos de materiais diferentes ao cobre [6].

O objetivo desse artigo é avaliar o desempenho da usinagem por NDE através de parâmetros como: taxa de remoção de material (TRM), taxa de desgaste (TD) e desgaste volumétrico relativo (DVR), bem como determinar a espessura da zona refundida e da zona afetada pelo calor (ZAC) durante o processo para eletrodo peça em aço SAE 52100 esferoidizado e temperado e revenido, ambos com eletrodo ferramenta de cobre eletrolítico.

\section{MATERIAIS E MÉTODOS}

\subsection{Usinagem dos eletrodos peça e ferramenta}

Definiu-se o aço SAE 52100 como material de base para fabricação dos eletrodos peça que foram usados no processo de nitretação por descargas elétricas. Para o eletrodo ferramenta utilizou-se cobre eletrolítico e os dois eletrodos foram usinados por processo convencional no laboratórios do CEFET-MG em formato cilíndrico.

\subsection{Processamento térmico do aço SAE 52100}

O material recebido na condição esferoidizado foi tratado termicamente no laboratório do CEFET-MG. Primeiramente, realizou-se a têmpera com temperatura de austenitização de $850^{\circ} \mathrm{C}$ durante 30 minutos e posterior resfriamento em óleo com agitação e aquecimento. O revenimento foi realizado após a têmpera com temperatura de $150 \stackrel{\circ}{\circ}$ por 2 horas. Utilizaram-se dois grupos de eletrodos peça com processamentos térmicos diferentes e que foram combinados com o eletrodo ferramenta de cobre eletrolítico. A Tabela 1 especifica eletrodo, dimensões e materiais utilizados:

Tabela 1. Especificações das dimensões dos eletrodos e material utilizado

\begin{tabular}{|c|c|c|}
\hline Dimensões & Eletrodo peça & Material \\
\hline Diâmetro $(\mathbf{m m})$ & 19 & Esferoidizado \\
\hline Comprimento $(\mathbf{m m})$ & 13 & Temperado e revenido \\
\hline & Eletrodo ferramenta & \\
\hline Diâmetro $(\mathbf{m m})$ & 22 & $\begin{array}{c}\text { Cobre } \\
\text { Eletrolítico }\end{array}$ \\
\hline Comprimento $(\mathbf{m m})$ & 30 & \\
\hline
\end{tabular}

\subsection{Procedimento da Nitretação por descargas elétricas}

Realizaram-se os testes em uma máquina de eletroerosão por penetração de modelo Servspark Eletroplus EDM-540, como mostrada na Figura 1, na qual possui uma cuba auxiliar com capacidade de 80 litros e fabricada em aço inoxidável AISI 304.A cuba auxiliar é usada para separar a solução de água deionizada e ureia do contato com o fluido dielétrico da máquina, evitando contaminações com o reservatório principal, corrosão devido ao uso da ureia e contaminação em testes realizados com outros tipos de fluido diéletricos. 


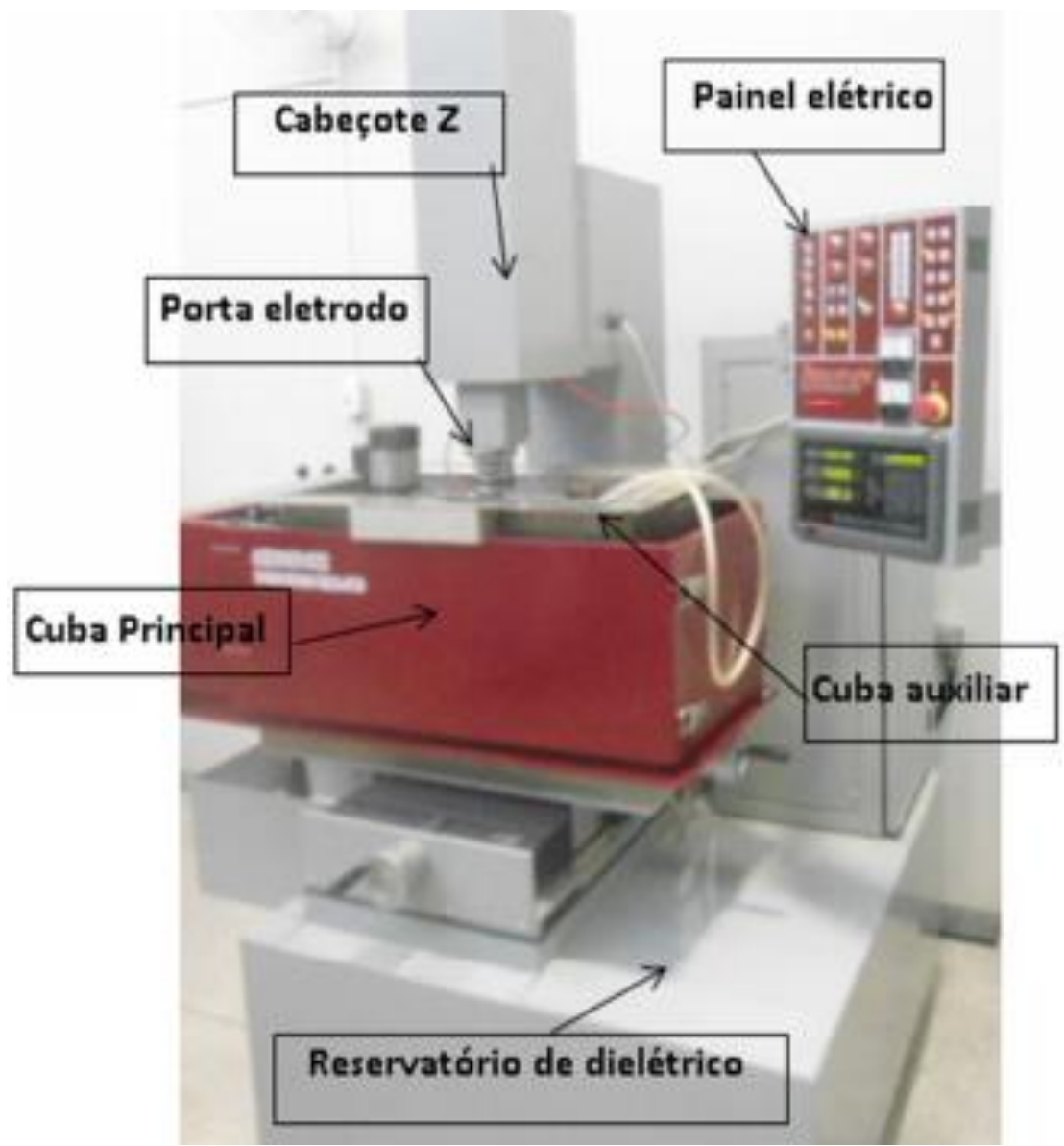

Figura 1. Máquina de eletroerosão por penetração (modelo Servspark Eletroplus EDM-540).

A Figura 2 apresenta o dispositivo porta eletrodo ferramenta no interior da cuba auxiliar, feito de cobre eletrolítico e para a realização dos testes, utlizou uma solução composta de água deionizada e ureia de concentração $30 \mathrm{~g} / \mathrm{l}$.Posicionou-se uma bomba centrífuga no interior da cuba auxiliar para agitação do fluido dielétrico que tem como objetivo a limpeza da fenda de trabalho.

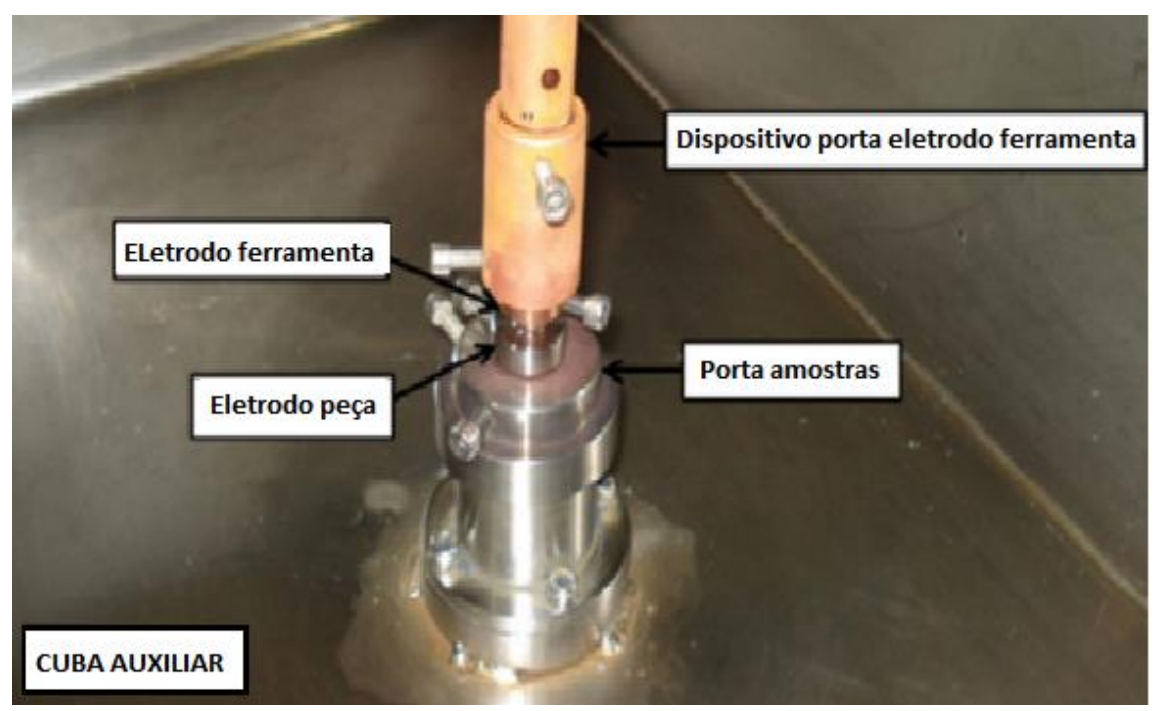

Figura 2. Detalhe interno da cuba auxiliar e fixação do eletrodo ferramenta. 
Ajustaram-se os parâmetros operacionais no painel eletrônico da máquina de eletroerosão, permitindo o controle de corrente de descarga,com corrente máxima de $40 \mathrm{~A}$, tensão de $75 \mathrm{~V}$ e durante o tempo de 10 minutos para cada teste

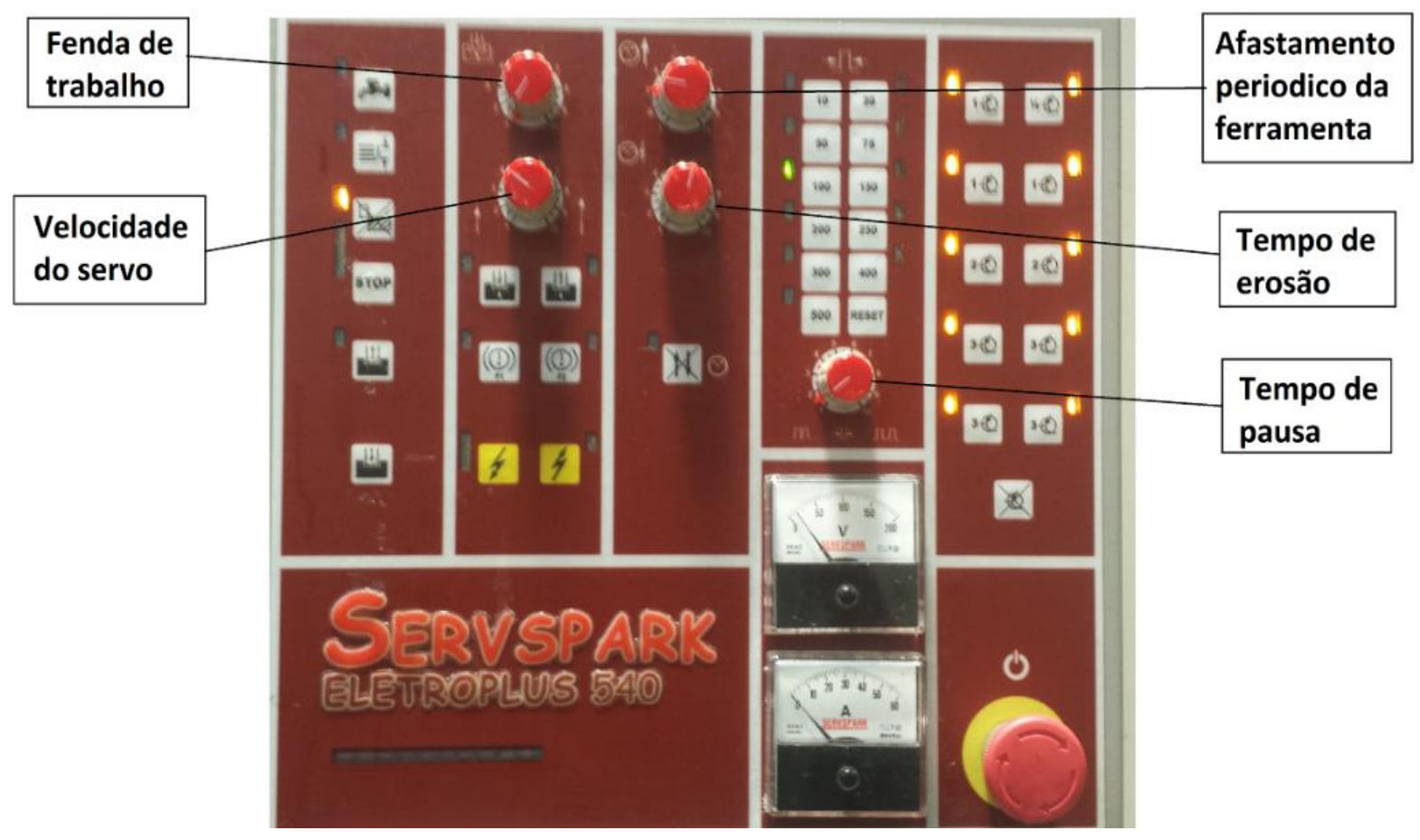

Figura 3. Indicação dos parâmetros ajustados no painel da máquina.

A figura 3 demonstra os parâmetros que foram ajustados diretamente no painel da máquina e os valores estão resumidos na Tabela 2.

Tabela 2. Parâmetros ajustados na máquina para realização do processo NDE

\begin{tabular}{|c|c|}
\hline Parâmetros & Valores \\
\hline Polaridade do eletrodo ferramenta & Positiva $(+)$ \\
\hline Tensão $(\mathrm{V})$ & 75 \\
\hline Corrente $(\mathrm{A})$ & 40 \\
\hline Tempo de pulso (Ton) $(\mu \mathrm{s})$ & 100 \\
\hline Tempo de pausa ( $\mathrm{\text {off }})$ & 1,5 \\
\hline Fenda de trabalho (gap) & 1 \\
\hline Velocidade do servo & 4 \\
\hline Afastamento periódico da ferramenta $(\mathrm{mm})$ & 3 \\
\hline Tempo de erosão $(\mathrm{s})$ & 6 \\
\hline
\end{tabular}

Mediu-se a condutividade elétrica inicial da água e foi de $0,0 \mu \mathrm{S} / \mathrm{cm}$, adicionou-se ureia e preparou uma solução de concentração $30 \mathrm{~g} / \mathrm{l}$. Ao iniciar e no término do processo, mediram-se as condutividades das soluções para os eletrodos de cobre eletrolítico. A Tabela 3 apresenta os valores de condutividade elétrica medidos no processo de nitretação. 
Tabela 3. Valores de condutividade dielétrica medidos no processo NDE

\begin{tabular}{|c|c|c|c|c|}
\hline \multirow{3}{*}{ Eletrodo ferramenta } & \multicolumn{4}{|c|}{ Condutividade elétrica $(\boldsymbol{\mu S} / \mathbf{c m})$} \\
\cline { 2 - 5 } & \multicolumn{3}{|c|}{ Esferoidizado } & Temperado e revenido \\
\cline { 2 - 5 } & Antes & Após & Antes & Após \\
\hline Cobre eletrolítico & 28 & 50 & 28 & 52 \\
\hline
\end{tabular}

Mediram-se as massas dos eletrodos peça e ferramenta antes e após o processo de nitretação por descargas elétricas com uma balança digital com precisão de $1 \times 10^{-4} \mathrm{~g}$, marca BEL e modelo MARK M.

Seccionou-se uma amostra referência para cada condição com uma serra de disco cut-off após o enriquecimento da superfície para observação via microscopia óptica da zona refundida e zona afetada pelo calor (ZAC), mediu-se também a dureza com o ensaio de microdureza Vickers com carga de 50 gf por 20 s. Realizou-se difração de Raio-X (DRX) para a comprovação da formação dos nitretos de ferro e cromo. Por fim, calculou-se e comparou-se o desempenho do processo EDM de acordo com parâmetros usuais de usinagem.

Para a avaliação do rendimento do processo utilizam-se de parâmetros como a taxa de remoção de material (TRM) que determina o volume de material removido por tempo [mm $3 / \mathrm{min}]$, da taxa de desgaste (TD) que caracteriza o volume de material removido do eletrodo ferramenta por tempo $\left[\mathrm{mm}^{3} / \mathrm{min}\right.$ ] e o desgaste volumétrico relativo (DVR) que é razão entre a taxa de desgaste e a taxa de remoção de material (10), como representado na Equação 1:

$$
D V R=\frac{T D}{T R M} \times 100[\%]
$$

\section{RESULTADOS E DISCUSSÃO}

Os resultados a seguir referem-se a nitretação por descargas elétricas no aço SAE 52100 esferoidizado, temperado e revenido como eletrodo peça e o cobre eletrolítico como eletrodo ferramenta.

\subsection{Microcopia Óptica e Dureza Vickers}

As amostras esferoidizadas e amostras temperadas e revenidas após o processo NDE foram caracterizadas por microscopia óptica, as imagens captadas após ataque com reagente químico nital 3\% estão representadas na Figura 4.Nas imagens notam-se a adesão de micro partículas na superfície formando uma zona refundida e logo abaixo percebe-se alterações microestruturais, região com cor mais escura denominada zona afetada pelo calor (ZAC).O fenômeno é atribuído a contaminações de materiais do eletrodo ferramenta e também ao gradiente de carbono, contribuindo para complexas alterações na região $[6,7]$. 

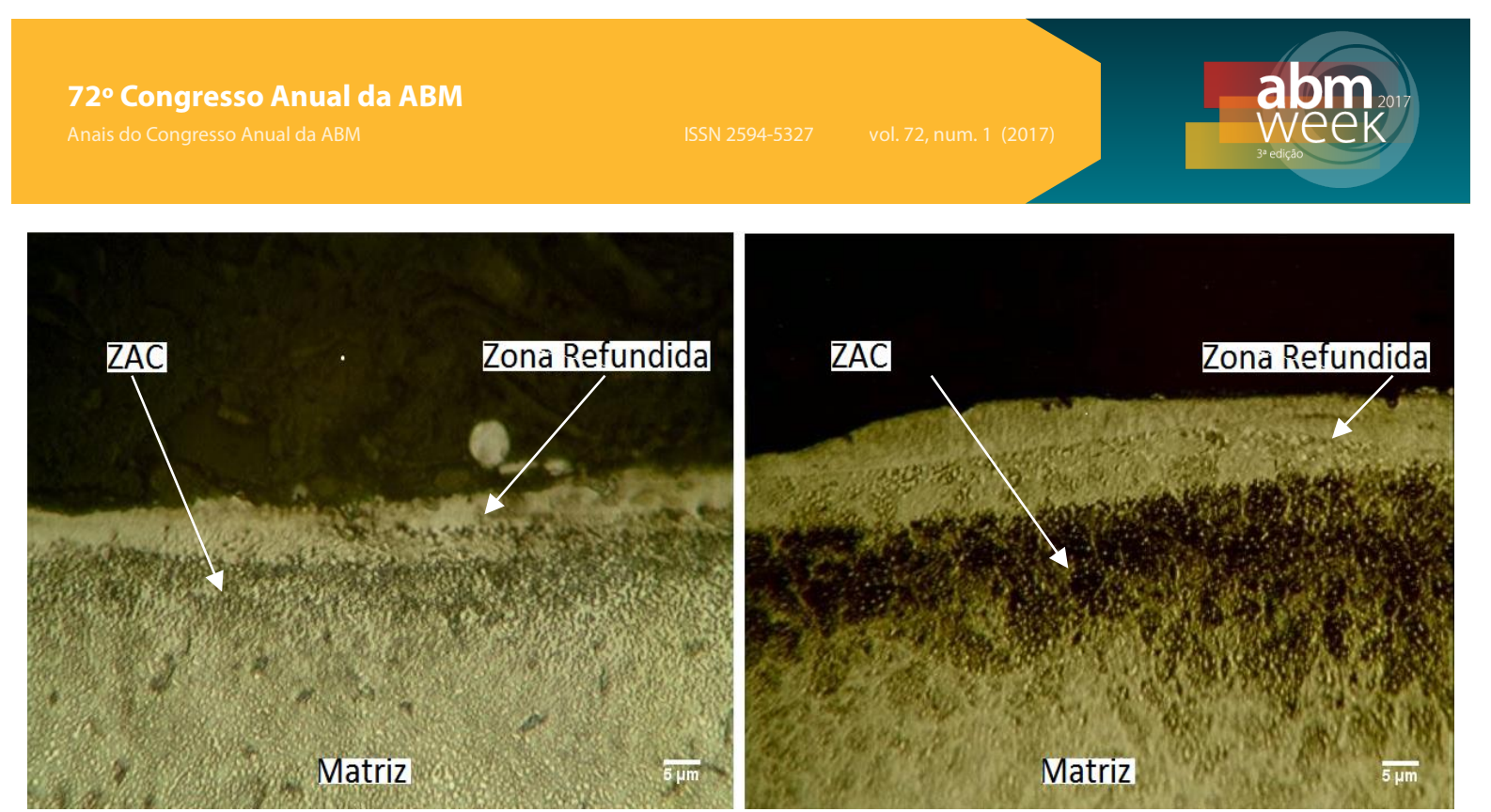

Figura 4. Camada Refundida formada durante a nitretação com ampliação de $400 \mathrm{X}$ e ataque com o reagente Nital 3\%. a) Eletrodo peça esferoidizado b) Eletrodo peça temperado e revenido, ambos com eletrodo ferramenta de cobre.

As espessuras aproximadas das camadas refundidas e das zonas afetadas pelo calor para os dois eletrodos peça estão resumidos na Tabela 4. Com isso, percebe-se que o material temperado e revenido apresentou maiores espessuras tanto da zona refundida quanto da zona afetada pelo calor.

Tabela 4. Valores das espessuras da zona refundida e zona afetada pelo calor dos eletrodos peça

\begin{tabular}{|c|c|c|c|}
\hline \multicolumn{3}{|c|}{ Eletrodos peça } \\
\hline \multicolumn{2}{|c|}{ Esferoidizado } & \multicolumn{2}{c|}{ Temperado e revenido } \\
\hline Zona refundida $(\mu \mathrm{m})$ & $7,5 \pm 1,2$ & Zona refundida $(\mu \mathrm{m})$ & $11,1 \pm 2,1$ \\
\hline ZAC $(\mu \mathrm{m})$ & $7,3 \pm 1,6$ & ZAC $(\mu \mathrm{m})$ & $17,8 \pm 3,2$ \\
\hline
\end{tabular}

A Tabela 5 resume os valores de dureza Vickers medidos nas regiões características apresentadas anteriormente na Figura 3. Para os dois eletrodos peça a região que apresentou maior dureza foi a zona refundida, sendo que o material esferoidizado teve um aumento de dureza de aproximadamente $126 \%$ e o temperado e revenido apresentou dureza $11 \%$ maior ambos em relação a matriz. É devido a rápida solidificação na superfície, propiciando a formação de martensita no aço usado como eletrodo peça, bem como a estruturas mais refinadas com maior resistência mecânica (6). Já para zona afetada pelo calor (ZAC) percebe-se que o aço esferoidizado apresentou dureza $83 \%$ maior em relação a matriz o que pode ser atribuído a formação de nitretos na região e a mudanças na microestrutura que teve como consequência aumento de resistência mecânica. No caso do eletrodo peça temperado e revenido o balanço de resistência mecânica entre a formação de nitretos e mudança na microestrutura fez com que houvesse diminuição da dureza em relação a matriz, explicado pelo o resfriamento mais lento em relação a superfície facilitando a difusão de carbono e diminuindo a resistência mecânica. 
Tabela 5. Valores de microdureza Vickers medidos zona refundida, zona afetada pelo calor dos eletrodos peça e matriz para os dois eletrodos peça

\begin{tabular}{|c|c|c|c|}
\hline \multicolumn{4}{|c|}{ Eletrodos peça } \\
\hline \multicolumn{2}{|c|}{ Esferoidizado } & \multicolumn{2}{c|}{ Temperado e revenido } \\
\hline Zona refundida (HV) & $735,5 \pm 5,0$ & Zona refundida (HV) & $906,0 \pm 6,0$ \\
\hline ZAC (HV) & $596,0 \pm 3,1$ & ZAC (HV) & $685,0 \pm 4,2$ \\
\hline Matriz (HV) & $325,0 \pm 4,4$ & Matriz (HV) & $813,0 \pm 6,0$ \\
\hline
\end{tabular}

\subsection{Difração de Raio-X}

A Figura 5 apresenta os espectros de Raio- $X$ das amostras analisadas. Os picos demonstram que para o eletrodo peça esferoidizado e material temperado e revenido após nitretação por descargas elétricas houve formação de nitretos de ferro e cromo em comparação com o material do substrato (referência) antes do processo.

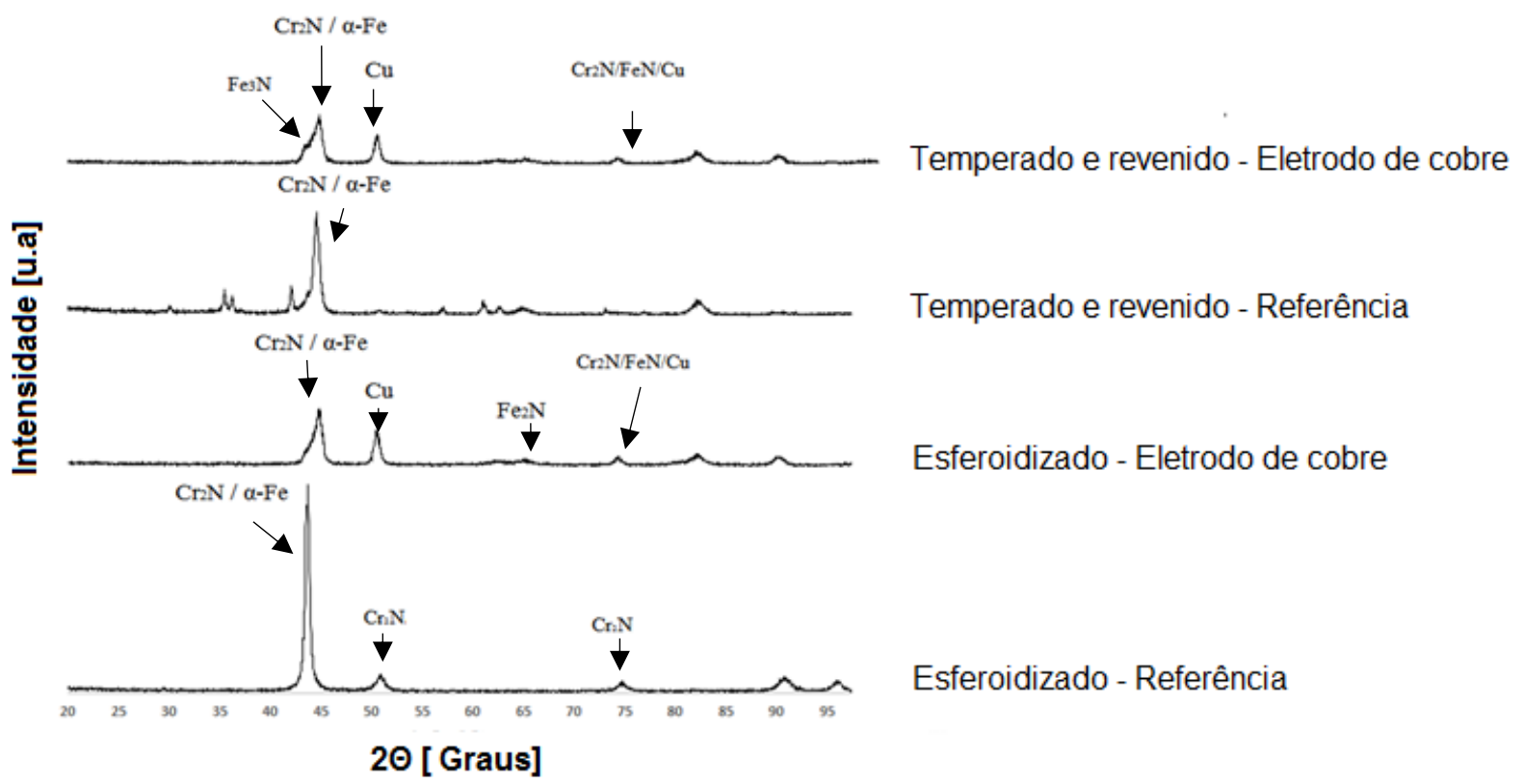

Figura 5. Espectros de Raio-X para as amostras SAE 52100 normalizada e temperado e revenido.

\subsection{Desempenho na Usinagem EDM}

Os resultados da média e desvio padrão da Taxa de Remoção de Material (TRM), Taxa de Desgaste do eletrodo ferramenta (TD) e Desgaste Volumétrico Relativo (DVR) são mostrados na Tabela 6 para usinagem por descargas elétricas para o tempo de 10 min e utilizando como fluido dielétrico uma solução de água deionizada e ureia de concentração $30 \mathrm{~g} / \mathrm{l}$.

Tabela 6. Desempenho na usinagem EDM para o aço SAE 52100 esferoidizado, temperado e revenido

\begin{tabular}{|c|c|c|c|}
\hline Esferoidizado & $\begin{array}{c}\text { Média } \pm \text { Desvio } \\
\text { Padrão }\end{array}$ & $\begin{array}{c}\text { Temperado e } \\
\text { revenido }\end{array}$ & $\begin{array}{c}\text { Média } \pm \text { Desvio } \\
\text { Padrão }\end{array}$ \\
\hline TRM (mm $\mathbf{3}$ min.) & $33,5 \pm 3,2$ & TRM $\left(\mathbf{m m}^{3} / \mathbf{m i n}.\right)$ & $51,6 \pm 1,6$ \\
\hline TD $\left(\mathbf{m m}^{\mathbf{3}} / \mathbf{m i n}.\right)$ & $3,9 \pm 0,6$ & TD $\left(\mathbf{m m}^{3} / \mathbf{m i n}.\right)$ & $5,2 \pm 0,6$ \\
\hline DVR $(\%)$ & $11,8 \pm 2,4$ & DVR $(\%)$ & $10,1 \pm 1,3$ \\
\hline
\end{tabular}


Percebe-se que o eletrodo peça temperado e revenido apresentou maior taxa de remoção de material do que o eletrodo peça esferoidizado. Para a taxa de desgaste do eletrodo ferramenta, o eletrodo peça esferoidizado, apresentou menor desgaste do eletrodo ferramenta e para o desgaste volumétrico relativo os valores não apresentaram diferenças significativas.

\section{CONCLUSÃo}

O processo NDE promoveu a formação uma camada nitretada na superfície dos eletrodos peça esferoidizado e eletrodo peça temperado e revenido como comprovado pelos espectros de raio-x a formação de nitretos de ferro e cromo. A espessura da camada nitretada total é composta pela soma dos valores da zona refundida e zona afetada pelo calor, os valores medidos aproximados foram $14,8 \mu \mathrm{m}$ para o eletrodo esferoidizado e $28,9 \mu \mathrm{m}$ para o eletrodo temperado e revenido.

A microdureza Vickers (HV) comprovou que houve aumento de resistência mecânica da zona refundida em relação a matriz, o eletrodo temperado e revenido apresentou aumento de $11 \%$ e o eletrodo esferoidizado de $126 \%$. Para a zona afetada pelo calor (ZAC) em relação a matriz, o eletrodo de esferoidizado apresentou aumento de dureza de $83 \%$ e o temperado e revenido apresentou dureza $16 \%$ menor.

Para o desempenho do processo EDM aplicado a nitretação por descargas elétricas comparando os eletrodos, tem-se que eletrodo temperado e revenido apresentou a taxa remoção de material e taxa de desgaste menores que o esferoidizado. Os desgastes volumétricos relativos não apresentaram diferenças significativas e estão dentro do desvio padrão.

\section{Agradecimentos}

Ao CEFET-MG pelo financiamento da bolsa de mestrado e auxílio à pesquisa. A Financiadora de estudos e projetos (FINEP).

\section{REFERÊNCIAS}

1 Castro VV. Avaliação da resistência ao desgaste dos aços SAE 52100 e SAE 1045 lubrificados com biodiesel e óleo diesel comercial [ dissertação de mestrado]. Porto Alegre: Pontifícia Universidade Católica do Rio Grande do Sul;2015.

2 Silva P. Análise do Comportamento em Fadiga do Aço SAE 52100 sob Diferentes Condições Microestruturais [tese de doutorado]. Rio Grande do Sul: Universidade Federal do Rio Grande do Sul;2001.

3 Zum Gahr KH. Microstructure and wear of materials. Amsterdam: Elsevier; 1987.

4 Holmberg K, Matthews A. Coatings tribology: properties, mechanisms, techniques and applications in surface engineering. 2. ed. Helsinki e Sheffield: Elsevier Science; 2008. p.576

5 Kumar S, Singh R.; Singh TP, Sethi BL.Surface modification by electrical discharge machining: a Review. Journal of Materials Processing Technology. 2009; 209:36753687.

6 Santos RF. Nitretação por EDM do aço AISI 4140[tese de doutorado]. Uberlândia: Universidade Federal de Uberlândia; 2013 
7 Lim LC, Lee LC, Wong YS, Lu HH. Solidification Microstructure of Eletrodischarge Machined Surfaces of Tools Steels. Materials Science and Technology. 1991; 7:239248.

8 Raslan AA, Santos RF, SILVA ER. Método de Nitretação através da Usinagem com descargas elétricas-NDE. FAPEMIG.2012.

9 Santos CE. Influência da corrente elétrica no processo de nitretação por descargas elétricas do AÇO AISI H13. [dissertação de mestrado]. Belo Horizonte: Centro Federal de Educação Tecnológica de Minas Gerais; 2015.

10 Amorim FL. Tecnologia de eletroerosão por penetração da liga de alumínio AMP 8000 e da liga de cobre. CuBe para ferramentas de moldagem de materiais plásticos [tese de doutorado]. Florianópolis: Universidade Federal de Santa Catarina;2002. 